\title{
PENGUKURAN JARAK BERBASISKAN STEREO VISION
}

\author{
Iman H. Kartowisastro \\ Jurusan Sistem Komputer, Fakultas Ilmu Komputer, Universitas Bina Nusantara \\ Jln. Kebon Jeruk Raya No. 27, Kebon Jeruk, Jakarta Barat 11530 \\ imanhk@binus.edu
}

\begin{abstract}
Measuring distance from an object can be conducted in a variety of ways, including by making use of distance measuring sensors such as ultrasonic sensors, or using the approach based vision system. This last mode has advantages in terms of flexibility, namely a monitored object has relatively no restrictions characteristic of the materials used at the same time it also has its own difficulties associated with object orientation and state of the room where the object is located. To overcome this problem, so this study examines the possibility of using stereo vision to measure the distance to an object. The system was developed starting from image extraction, information extraction characteristics of the objects contained in the image and visual distance measurement process with 2 separate cameras placed in a distance of $70 \mathrm{~cm}$. The measurement object can be in the range of $50 \mathrm{~cm}-130 \mathrm{~cm}$ with a percentage error of 5:53\%. Lighting conditions (homogeneity and intensity) has a great influence on the accuracy of the measurement results.
\end{abstract}

Keywords: stereo vision, curve fitting, correlation, Look-Up Table, distance measurement.

\begin{abstract}
ABSTRAK
Pengukuran jarak dari keberadaan sebuah objek memiliki berbagai cara, antara lain dengan memanfaatkan sensor pengukur jarak seperti ultrasonic sensor, maupun dengan menggunakan pendekatan berbasiskan vision system. Cara yang terakhir ini memiliki kelebihan dalam hal flexibilitas yaitu objek yang dipantau relatif tidak memiliki batasan-batasan karakteristik bahan yang digunakan sekaligus juga memiliki kesulitan tersendiri dikaitkan dengan orientasi objek dan keadaan ruangan dimana objek tersebut berada. Untuk mengatasi masalah ini, maka dalam penelitian ini dikaji kemungkinan dilakukannya penggunaan stereo vision untuk melakukan pengukuran jarak terhadap sebuah objek. Sistem yang dikembangkan dimulai dari proses penangkatan citra, ekstraksi informasi karakteristik dari objek yang terdapat dalam citra dan proses pengukuran jarak secara visual dengan menggunakan 2 buah kamera yang diletakan terpisah dengan jarak 70 $\mathrm{cm}$. Pengukuran objek dapat dilakukan dalam kisaran $50 \mathrm{~cm}-130 \mathrm{~cm}$ dengan prosentase kesalahan sebesar 5.53\%. Kondisi pencahayaan (homogenitas dan intensitas) memberikan pengaruh yang besar terhadap akurasi hasil pengukuran.
\end{abstract}

Kata-kunci : stereo vision, curve fitting, korelasi, Look-Up Table, pengukuran jarak. 


\section{PENDAHULUAN}

Penetrasi dari service robot kedalam pasar komersial saat ini memiliki peningkatan yang lebih besar daripada industrial robot. Seiring dengan perkembangan service robot ini, maka salah satu dari bidang robotika, yaitu robot vision menjadi bidang yang semakin menarik untuk digeluti. Area yang banyak dilakukan salah satunya adalah untuk mengetahui keberadaan dan jarak dari sebuah objek secara visual. Perolehan informasi mengenai jarak menjadi penting bagi sebuah robot karena merupakan dasar agar robot tersebut dapat mendeteksi adanya objek di sekitarnya. Pengukuran jarak dari sebuah objek sebetulnya dapat pula dilakukan secara non visual, seperti dengan menggunakan menggunakan sensor ultrasonik (Serikawa, Morita, Nakashi, dan Nakamura, 2005), sensor infra merah (Benet, Blanes, Simo, dan Perez, 2001) dan laser (Antonio, 1994).

Vision system dengan CCD camera dapat digunakan untuk melakukan pengamatan dalam area yang luas (Cheng, et al, 2008), namun pengkuran jarak dengan vision system memiliki potential problem, antara lain dalam melakukan interpretasi bentuk 3 dimensi berdasarkan citra 2 dimensi (Laurentini, 1995: 188-195). Issue permasalahan dalam 3 dimensi dapat dipecahkan dengan menggunakan pendekatan stereo vision, yaitu digunakannya 2 buah kamera yang diletakan dalam posisi berbeda untuk dapat melakukan ekstraksi fitur 3 dimensi. Namun demikian salah satu problem dalam menggunakan stereo vision system adalah perlu nya dilakukan proses kalibrasi yang tidak sederhana untuk memperoleh hasil yang optimal. Algoritma berbasiskan Genetic Algorithm telah dicoba untuk digunakan dalam memperoleh kalibrasi dengan presisi tinggi dalam streo vision system (Zhou, Tan, \& Gao 1995).

Dalam makalah ini, disampaikan perancangan sistem pengukurun objek dengan menggunakan stereo vision system yang diterapkan pada objek sederhana berbentuk kubus berukuran $7 \mathrm{~cm} \times 7 \mathrm{~cm} \mathrm{x} \mathrm{t}$ $\mathrm{cm}$. Makalah ini didasarkan pada kegiatan yang pernah dilakukan sebelumnya (Salim, Suriani dan Andianto, 2009).

\section{METODE}

Kegiatan penelitian ini merupakan perancangan sebuah sistem dimana penelitian dilakukan untuk mengetahui perbedaan yang mungkin terjadi (robustness) antara perancangan diatas kertas dengan kenyataan yang terjadi dalam kondisi nyata.

Didalam merancang sistem pengukuran jarak ini, proses yang dijalankan dimulai dengan penangkapan citra (image capture) oleh 2 buah kamera, yang selanjutnya gambar tersebut akan diperbaiki kualitas gambarnya dan dimanipulasi agar dapat diperoleh karakteristik yang dibutuhkan melalui proses pengolahan citra (image enhancement and description). Setelah diperoleh citra dengan karakteristik tertentu, maka dilakukan pemeriksaan apakah objek pada kedua citra (yang ditangkap oleh 2 kamera) tersebut merupakan objek yang sama (matching process). Matching process ini dilakukan dengan memperhatikan apakah ada korelasi dari object yang ditangkap oleh kamera 1 dengan objek yang ditangkap oleh kamera 2. Hal ini penting untuk dilakukan mengingat dalam kenyataan dilapangan, dapat terjadi kegagalan sistem apabila karena sesuatu hal, maka citra yang tertangkap oleh kedua kamera merupakan citra dari objek yang berbeda (misalnya karena kehadiran objek lain yang tidak disangka-sangka).

Setelah dipastikan bahwa objek yang terekam oleh kamera merupakan objek yang sama, maka barulan proses pengukuran jarak dapat dilakukan. Keseluruhan proses perancangan diatas dapat dilihat pada gambar 1 berikut : 


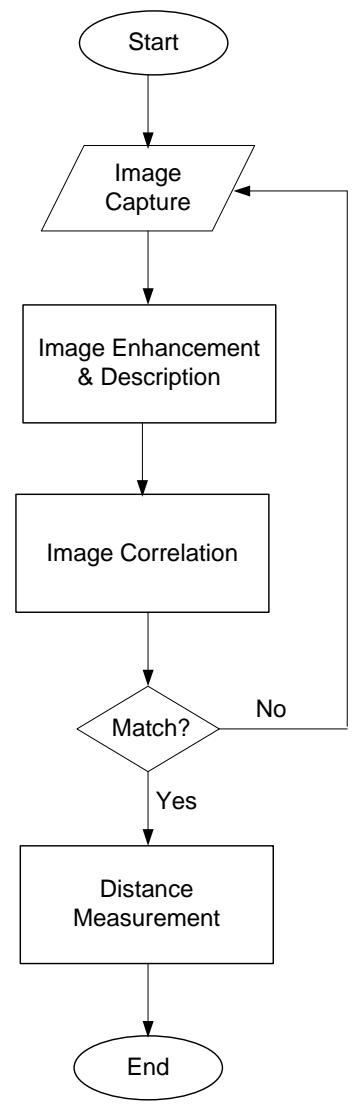

Gambar 1. Proses Perancangan Sistem

\section{Image Capture}

Sebuah citra ditangkap dengan menggunakan 2 buah kamera yang berkarakteristik sama namun diletakan terpisah dengan jarak $70 \mathrm{~cm}$ dan sudut kamera menghadap ke objek memiliki sudat terhadap garis normal sebesar $60^{\circ}$ sebagaimana terlihat pada gambar 2. Dengan berdasarkan trigoneometri sederhana, rumusan penentuan posisi kamera yaitu untuk mendapatkan jarak antar kamera dan sudut kamera yang baik sehingga dapat menghindari terjadinya out of frame condition (kamera tidak dapat menangkap gambar objek karena berada diluar area pandang kamera) adalah sebagai berikut (Salim, Suriani dan Andianto, 2009) :

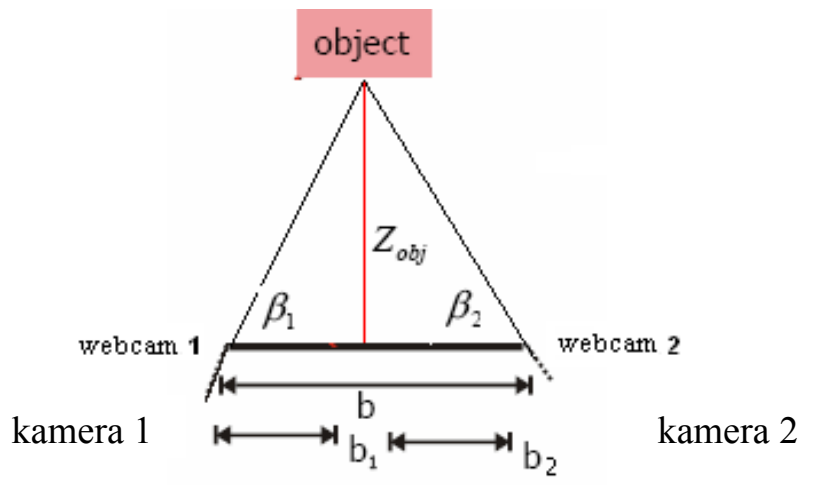

Gambar 2. Posisi dan Orientasi Kamera 
dimana :

Zobj = Jarak antara titik tengah kedua kamera dengan objek

$\beta_{1,2}$ : Sudut pandang kamera ke objek terhadap garis normal.

Agar menghasilkan korelasi yang baik, maka perlu dilakukan kalibrasi peletakan kamera yang dilakukan secara manual. Dalam kalibrasi ini, maka orientasi kamera diatur sedemikan rupa sehingga objek yang tertangkap pad kamera 1 dan kamera 2 memiliki posisi dan orientasi yang sama seperti terlihat pada pada gambar 3 .

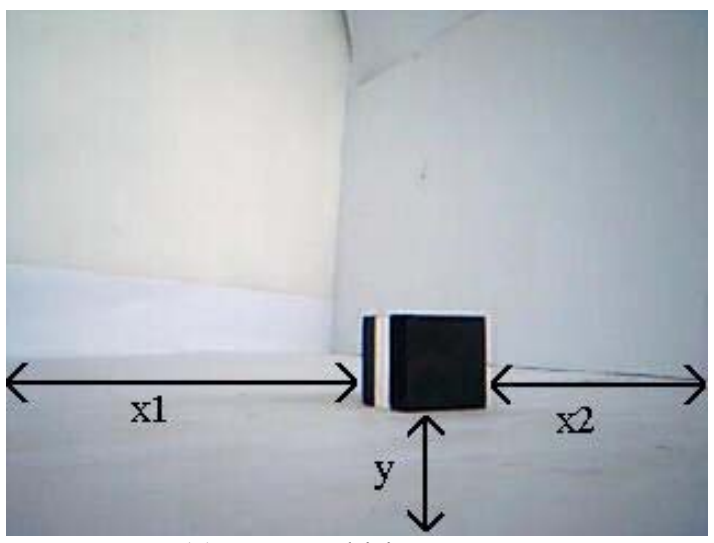

(a) Kamera kiri

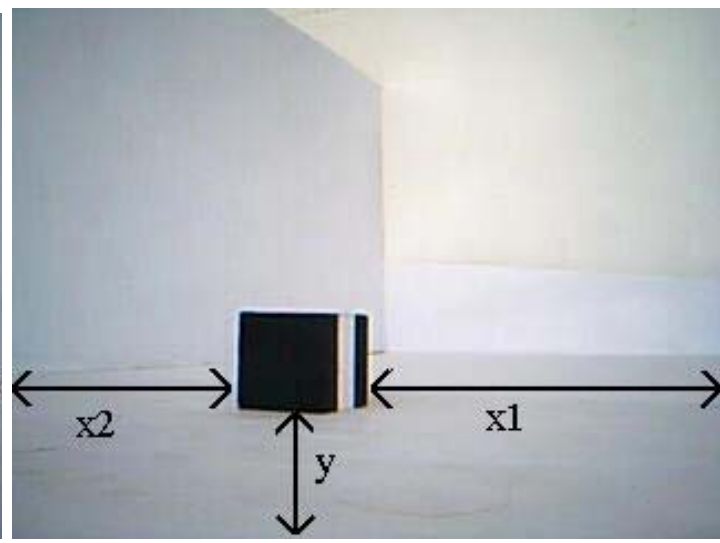

(b) Kamera kanan

Gambar 3. Kalibrasi kamera secara manual

Dengan mengatur nilai $\mathrm{x} 1, \mathrm{x} 2$, dan y pada objek yang ditangkap oleh kedua kamera yang diusahakan sama serta dengan pengamatan visual untuk memastikan orientasi objek yang ditangkap oleh kedua kamera adalah sama, maka selanjutnya kamera telah siap untuk digunakan dalam percobaan.

\section{Image Enhancement \& Description}

Proses pengolahan citra yang dilakukan pada dasarnya dibagi menjadi 2 bagian : 1) image enhancement, yaitu proses untuk memperbaikan kualitas citra dari objek, 2) image description, yaitu proses untuk dapat memperoleh karateristik dari objek yang terdapat dalam citra yang telah ditingkatkan kualitasnya tersebut..

Image enhancement yang dilakukan secara lebih rinci meliputi :

- grayscaling untuk mengubah nilai pixel dari warna (RGB) 24 bit menjadi gray-level 8 bit. Grayscaling dilakukan untuk mempermudah pengolahan gambar karena intensitas warna yang perlu diproses hanya ada dua, yaitu hitam dan putih saja. Pada dasarnya proses grayscaling dilakukan dengan meratakan nilai pixel dari 3 nilai RGB menjadi 1 nilai. Untuk memperoleh hasil yang baik, nilai pixel tidak langsung dibagi menjadi 3 melainkan terdapat persentase dari masing-masing nilai. Salah satu persentase yang sering digunakan adalah $29,9 \%$ dari warna merah, $58,7 \%$ dari warna hijau dan $11,4 \%$ dari warna biru. Nilai pixel didapat dari jumlah persentase 3 nilai tersebut.

- median filtering digunakan untuk menghilangkan noise. Median filtering bekerja dengan mengevaluasi tingkat brightness dari suatu pixel dan menentukan pixel mana yang tingkat kecerahannya adalah nilai median (nilai tengah) dari semua pixel.

Sedangkan untuk Image Description, maka proses yang dilakukan adalah edge detection yang digunakan untuk mendeteksi tepi-tepi dari objek yang ingin di ekstrak. Dasar untuk melakukan edge detection adalah mencari titik-titik pixel dalam gambar yang memiliki perubahan iluminasi yang besar, 
misalnya dari warna hitam menjadi warna putih, atau sebaliknya untuk gambar yang berformat grayscale. Untuk perlu diketahui perbedaan intensitas cahaya dari sebuah citra dengan menghitung gradient yang ada melalui persamaan :

$$
G[f(x, y)]=\left[\begin{array}{l}
G_{x} \\
G_{y}
\end{array}\right]=\left[\begin{array}{l}
\frac{\partial f}{\partial x} \\
\frac{\partial f}{\partial y}
\end{array}\right]
$$

Gradient ini diterapkan dengan menggunakan sebuah mask 3x3, yang lebih banyak dikenal sebagai Sobel operator (Gonzalez, Wintz, 1998) dimana operator ini digunakan untuk melakukan proses diferensiasi dari pixel pada seluruh objek yang dituju .

\section{Image Correlation}

Korelasi secara diskrit dilakukan dengan menggunakan algoritma yang diturunkan dari persamaan berikut (Gonzalez, Wintz, 1998) :

$$
f(x, y) \bullet g(x, y)=\sum_{m=0}^{M-1} \sum_{n=0}^{N-1} f^{*}(m, n) g(x+m, y+n)
$$

dimana $f(x, y)$ dan $g(x, y)$ masing-masing adalah citra dari objek yang ditangkap oleh kamera 1 dan kamera 2.

Dengan melakukan pendekatan konservatif, maka kondisi match (objek yang ditangkap oleh kedua kamera merupakan objek yang sama) dinyatakan terjadi, bila

$$
f(x, y) \bullet g(x, y) \geq 0.5
$$

Bila sistem menyetakan bahwa kondisi match terjadi, maka selanjutnya akan dilakukan proses pengukuran jarak.

\section{Distance Measurement}

Proses pengukuran jarak akan dilakukan jika pada proses cross correlation disimpulkan objek yang di tangkap oleh kedua kamera adalah objek yang sama.

Pengukuran jarak dilakukan menggunakan pendekatan curve fitting dengan memanfaatkan sebuah Look-Up Table (database). Look up Table ini merupakan sekumpulan data yang membentuk fungsi antara jumlah pixel hitan dari objek yang tertangkap kamera pada beberapa jarak tertentu. Objek yang berjarak jauh maka memiiki jumlah pixel yang kecil, sebaliknya objek yang berjarak dekant memiliki jumlah pixel yang besar. Berdasarkan sample data inilah selanjutnya dilakukan proses curve fitting sehingga dapat diperoleh persamaan garis yang memenuhi sample data tersebut.

\section{HASIL DAN PEMBAHASAN}

Setelah melakukan proses perancangan sistem, maka selanjutnya dilakukan implemtasi yang bertujuan untuk mengetahui apakah sistem yang dirancang dapat digunakan pada keadaan nyata dilapangan. Bila dalam perancangan kondisi yang digunakan adalah kondisi yang mendekati ideal, maka dalam implementasi akan dilakukan beberapa pengujian dan evaluasi untuk mengetahui apakah sistem memiliki ketahanan (robustness) terhadap kondisi nyata dimana kondisi pencahayaan dapat berubah-ubah. 
Sistem yang dirancang dicobakan dalam pengukuran jarak objek dimana objek diletakan dalam rentang $50 \mathrm{~cm}-130 \mathrm{~cm}$ dan selanjutnya dilakukan pengukuran. Dengan pertimbangan praktikalitas (simplicity), maka proses pengukuran jarak dilakukan dengan menggunakan metode curve fitting $4^{\text {th }}$ polynomial.. Dilakukan pengukuran sebanyak 6 buah jarak berbeda yang dilakukan secara sembarang diantara rentang $50 \mathrm{~cm}-130 \mathrm{~cm}$. Semakin dekat objek dengan kamera, maka dimensi dari objek semakin besar, sehingga jumplah pixel yang terekam juga semakin besar. Selanjutnya dilakukan proses curve fitting untuk mendapatkan karakteristik hubungan antara jarak dan jumlah pixel diantara rentang $50 \mathrm{~cm}-130 \mathrm{~cm}$ sebagai terlihat dalam gambar4 dibawah.

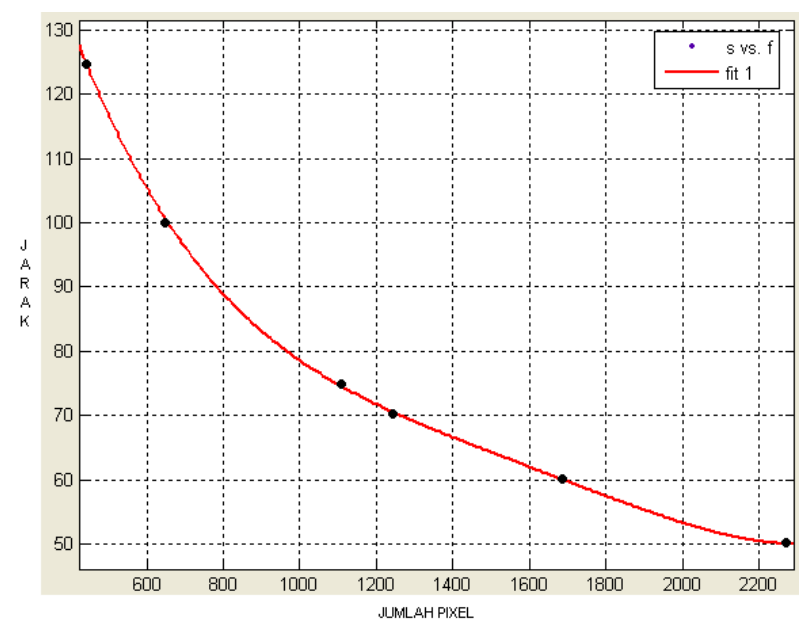

Gambar 4 Kurva karakteristik jarak vs. jumlah pixel.

Bila pada tahap perancangan, sistem dikembangkan berdasarkan keadaan pencahayaan yang terang dan mendekati homogen (siang hari jam 12), maka selanjutna dalam percobaan dilakukan evaluasi sistem tersebut pada tiga kondisi cahaya yang berbeda, yaitu jam 10.30 (pencahayaan sedang), jam 12.00 (pencahayaan terang dan homogen dan pada jam 16.00 (pencahayaan redup). Hasil dari percobaan ini dapat dilihat pada gambar 5, 6 dan 7 dibawah.

Persentase kesalahan yang merupakan perbedaan antara jarak yang sebenarnya dan jarak terukur, dapat dihitung sebagai berikut :

$\%$ Kesalahan $=(($ abs $($ Jarak Terukur-Jarak Sebenarnya $) /$ Jarak Sebenarnya $) * 100 \%$

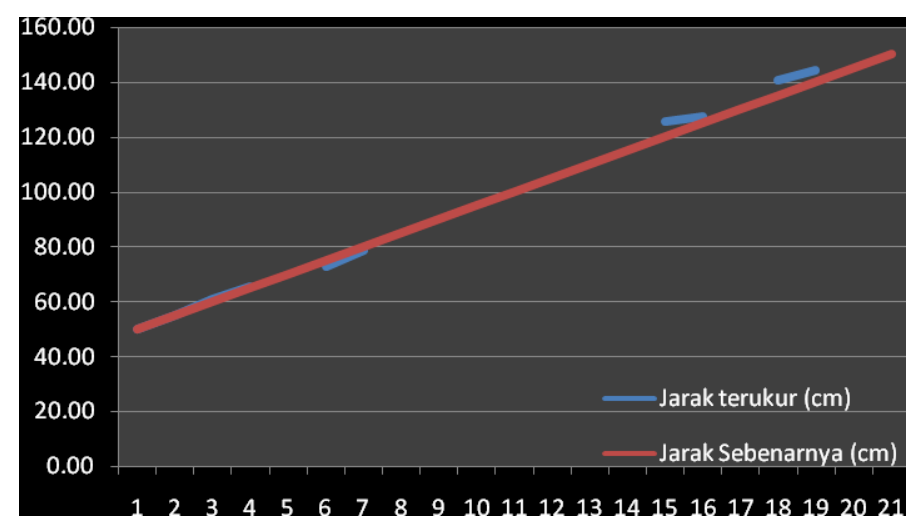

Gambar 5 Jarak terukur vs. Jarak sebenarnya pada jam 10.30, prosentase kesalahan 20.86\% 


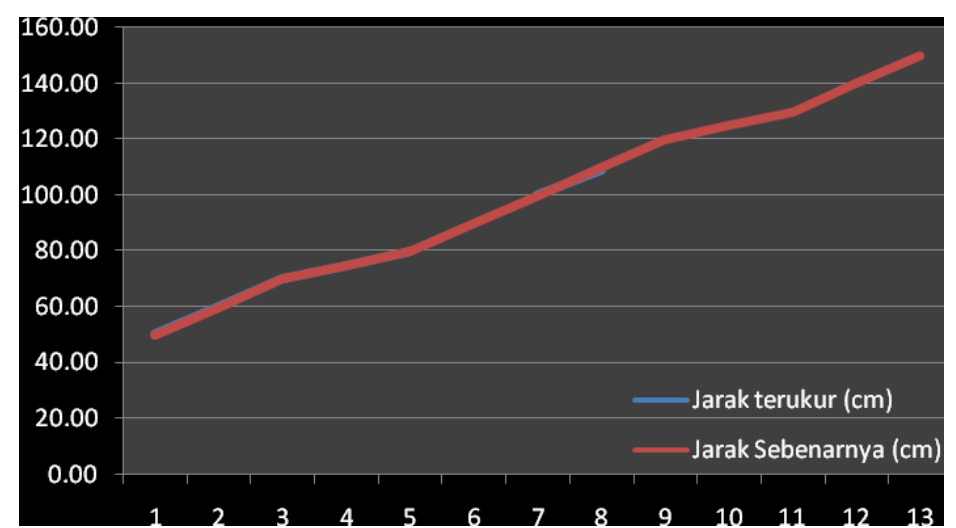

Gambar 6 Jarak terukur vs. Jarak sebenarnya pada jam 12.00, prosentase kesalahan 5,53\%

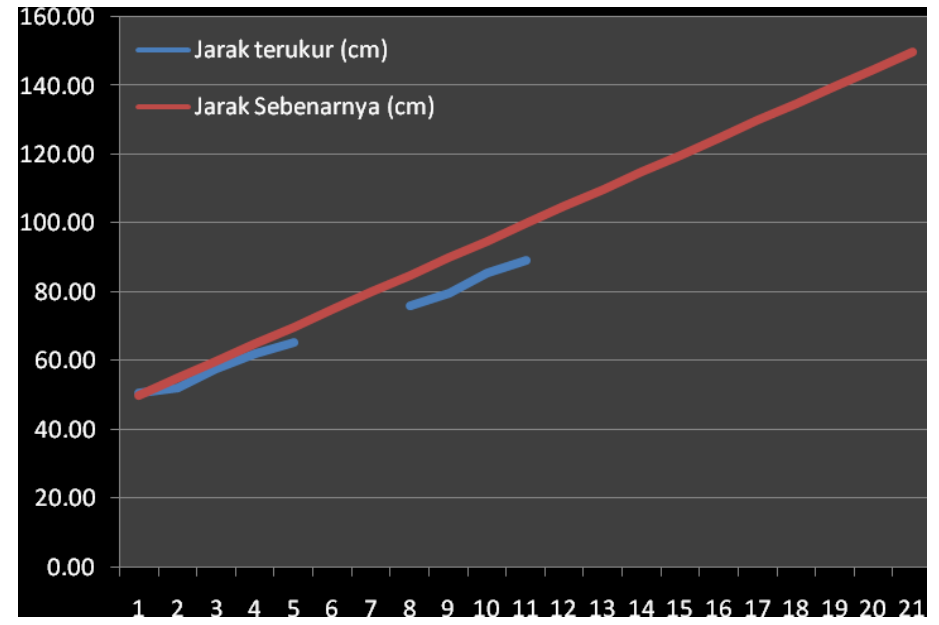

Gambar 7 Jarak terukur vs. Jarak sebenarnya pada jam 16.00, prosentase kesalahan $74.25 \%$

Hasil evaluasi menunjukan pengujian yang dilakukan berdasarkan kondisi saat sistem dirancang, memiliki prosentasi kesalahan $5.53 \%$ dan dalam pengamatan secara visual tidak terdapat perbedaan antara jarak yang sebenarnya dengan jarak yang terukur. Pengujian yang dilakukan dalam kondisi pencahayaan yang berbeda, yaitu pada jam 10.30 dan jam 16.00 memberikan prosentasi kesalahan yang lebih besar, yaitu masing-masing $20.86 \%$ dan $74.25 \%$. Perbedaan ini disebabkan tidak hanya karena intensitas cahaya yang berbeda, tetapi juga kondisi homogenitas dari pencahayaan yang berbeda (adanya bayangan).

\section{PENUTUP}

\section{Simpulan}

Perancangan sistem pengukuran jarak secara visual berbasiskan stereo vision dengan menggunakan 2 buah kamera telah dilakukan. Objek kubus berukuran sisi $7 \mathrm{~cm}$ yang diletakan pada rentang jarak $50 \mathrm{~cm}-130 \mathrm{~cm}$ dapat diukur jaraknya secara visual dengan memanfaatkan Look Up Table yang memiliki prosentasi kesalahan 5.53\%. Namun demikian hasil percobaan menunjukan 
bahwa sistem ini hanya dapat bekerja dengan baik bila sistem pencahayaan yang digunakan bersifat homogen dengan intensitas cahaya yang sama dengan kondisi saat look up table dibangun..

Perlu diingat pula, bahwa proses peletakan kamera dan pelaksanaan kalibrasi yang dilakukan secara manual memberikan pengaruh yang besar terhadap proses matching mengingat proses correlation sangat bergantung terhadap posisi dan orientasi dari objek yang ditangkap oleh masingmasing kamera.

\section{Saran untuk kegiatan lebih lanjut}

Dengan melihat hasil pengujian dan evaluasi yang ada, berikut adalah saran-saran yang dapat dilakukan untuk kegiatan lebih lanjut :

- Peletakan kamera/ mounting system dapat digunakan dengan cara yang lebih baik.

- Penelitian lebih mendalam untuk menguji keberhasilan dan kegagalan dari matching process.

- Explorasi dalam mengembangkan algoritma pengukuran jarak secara visual.

\section{DAFTAR PUSTAKA}

Benet, G., Blanes, F., Simo, J. E., \& Perez, P., (2002). Using Infrared Sensors For Distance Measurement In Mobile Robots, Journal of Robotics and Autonomous System, Vol. 10, 2002, pp. 255-266.

Cheng, C. C., Ming, C. L., Chin, T. C., \& Chen, P. T. (2008) Vision Based Distance and Area Measurement System, WSEAS Transaction on Signal Processing, Issue 2, Volume 4, February 2008 .

Zhou, C., Tan, D., Gao, H. W. (2006). A High Precision Calibration and Optimization Method for Stereo Vision System, IEEE $9^{\text {th }}$ International Conference in Control, Automation, Robotics and Vision, Singapore 5-8 December 2006.

Gonzalez, R. C., \& Wintz, P. (1998). Digital Image Processing, Addison-Wesley Publishing Company.

Laurentini, A., (1995) How Far 3D Shapes Can Be Understood from 2D Silhouettes, IEEE Transactions on Pattern Analysis and Machine Intelligence, Vol. 17. No. 2, February 1995.

Salim, D., Suriani, V., \& Andianto, (2009). Pengukuran Jarak dengan Stereo Eyes, Final Project Report, Binus University, Computer Eng Dept..

Serikawa, S., Morita, K., Nakashi, K., \& Nakamura, R. (2005) A Method for Position Detection and Shape Recognition with Ultrasonic Sensor, International Symposium on Advanced Intelligent Systems. 